\title{
Teething induced fever in a 9-month old child: a case report
}

HARUNA I. DIKA ${ }^{*}$, SHABANI IDDI ${ }^{1}$ and NEEMA KAYANGE ${ }^{2,3}$

${ }^{1}$ Department of Physiology, Weill Bugando School of Medicine, Catholic university of Health and Allied Sciences, P. O. Box 1464, Mwanza, Tanzania

${ }^{2}$ Department of Pediatrics and Child Health, Bugando Medical Center, Mwanza, Tanzania

3 Department of Pediatrics and Child Health, Weill Bugando School of Medicine, Catholic university of Health and Allied Sciences, Mwanza, Tanzania

\begin{abstract}
The association between teething and fever has attracted considerable interest because studies have reported controversial results. These discordant results have posed a challenge in the management of fever occurring during teething. The objective of this paper is to supplement previous studies which showed association between teeth eruption and fever and highlight mismanagement of teething induced fever. A 9-month old baby girl presented with fever during teeth eruption. Despite of no malaria parasites seen on blood slide and lack of features and laboratory investigations suggestive of urinary tract infection or bacteremia, the child was treated with antimalarial drugs and prescribed antibiotics. This case study demonstrates that unrecognized teething induced fever leads to unnecessary use of anti-malarial drugs and antibiotics. We recommend paediatricians to consider teething as one of the causes of fever among children.
\end{abstract}

Keywords: Teething fever, child, management, Tanzania

\section{Introduction}

The association between teething and fever has attracted considerable interest because studies have reported controversial results (Jaber et al., 1992; Wake et al., 2000). For instance, a prospective cohort study in Israel found an association between fever and teeth eruption (Jaber et al., 1992), but a similar study among 6-24 months old children in Australia, failed to confirm the association (Wake et al., 2000). Paediatricians agree that fever and other systemic disturbances such as diarrhoea frequently do occur during teething but most of them consider the occurrence as coincidence or due to change in eating behaviour or stress and infections (Coreil et al., 1995). While current paediatric teaching and some studies have failed to recognize the existence of an association between fever and teething (Leung, 1989; Kliegman et al., 2007), lay persons and some medical personnel strongly believe that teething causes fever (Coreil et al., 1995; Wake et al., 1999). These controversial study results and conflicting views pose a challenge in the management of fever occurring during teething since an accurate treatment depends on understanding the cause of the disorder. Here we present a case, which may suggest a link between teething and fever. This case study complement previous studies which showed association between teeth eruption and fever and highlight mismanagement of teething induced fever.

\section{Case}

A 9-month old baby girl presented to Al-Jumaa Heath Centre, Mwanza, Tanzania, with a history of high grade fever, loss of appetite, restless and diarrhoea (passing loose stools 7 times per day)

\footnotetext{
*Correspondence E-mail: hdika2001@yahoo.co.uk
} 
for one day. The child was febrile (axillary temperature, $38.2^{\circ} \mathrm{C}$ ) and weighed $9.5 \mathrm{~kg}$. The child did not have any tooth and there was no other remarkable finding on physical examination. Upon investigations, no malaria parasites were observed under microscopic examination and malaria antigen (rapid diagnostic) test was negative. Urinalysis showed yellow urine, White Blood Cells sedimentation of 2-10 per high power field. Neither cysts nor trophozoids were seen in stool analysis. Despite of negative malaria tests, the child was covered on artemether and lumefantrine ( 1 tablet start, then second tablet after 8 hours followed by 1 tablet twice daily for next 2 days), paracetamol $125 \mathrm{mg}$ thrice daily and oral rehydration solutions. The mother was advised to breast feed the child more often.

On the third day, the child continued to have episodes of high fever and diarrhoea. The child was returned to hospital where blood and urine were collected for further investigations Full blood picture as well as blood and urine culture were performed. After blood and urine collection, the patient was prescribed Metronidazole 125mg thrice daily for 5 days. Full blood picture showed haemoglobin concentration of $11 \mathrm{mg} / \mathrm{dl}$, white blood cell count of 6.45 million per microliter (neutrophils $60.0 \%$, eosinophils $2.7 \%$, basophils $0.5 \%$, monocytes $7.1 \%$, and lymphocytes $29.7 \%$ ). No bacteria growth was observed in either blood or urine culture. Despite of these negative laboratory findings, the patient continued to have fever and diarrhoea and the mother hesitated to give her medication (metronidazole). On the fourth day, the mother noticed a pair of lower central incisor teeth erupted and on the fifth day, the child had neither fever nor diarrhoea.

A month later, the child experienced similar symptoms for 3 days before eruption of the upper central incisor teeth. This time, the child was given paracetamol syrup only, and symptoms subsided after teeth eruption. Although viral infections were not ruled out when the child had fevers which were followed by teeth eruption, the two coincidences of teeth eruptions preceded by fever suggests a likelihood that teething is associated with fever.

\section{Discussion}

While a number of paediatricians and other scholars consider systemic signs such as fever during teeth eruption to be merely coincident with period of teething (Wake et al., 2000; Wake \& Hesketh, 2002; Cunha et al., 2004; Kiran et al., 2011), the current case suggests that teething induces fever. The timing of fever and other symptom presented with, and their disappearance relative to first teeth eruption and lack of evidence of other causes of the fever strongly suggest that fever and other systemic disturbances in the present case were due to teething. Observation of this case study is in agreement with the prospective cohort study among apparently healthy infants which demonstrated an association between teething and fever (Jaber et al., 1992).

Tooth eruption is associated with many histological changes along the eruption pathway (Yoo et al., 2011). Gingival inflammation has been considered one of the clinical manifestations most commonly associated with teething (Oziegbe et al., 2009). Examinations of histological tissues have demonstrated that teething process is associated with a progressive inflammatory reaction in the periodontal tissue which causes soreness and swelling of the gums before tooth eruption (de França Landim et al., 2013). The fever occurring during teething is an integral part of the acute inflammatory reaction of teething process and is produced by cytokines (Shapira et al., 2003; Silveira \& Procianoy, 1998). Cytokines are small protein signalling molecules, which are known to induce fever (Krause et al., 1997). Cytokines whose levels in the circulation have been observed to increase during teething include interleukins (IL-1 $\alpha, I L-1 \beta)$ and tumour necrosis factors a [TNFa] (Shapira et al., 2003). Usually, cytokines stimulate production of prostaglandin E2 (PGE2) by the glial cells and endothelial cells by inducing the cyclooxygenase 2 (Elmquist et al., 1997). PGE2 alters the activity of thermo-sensitive neurons of the thermoregulatory centre of the 
pre-optic area in the hypothalamus to induce fever whereby it stimulates cold-sensitive neurons and inhibits heat-sensitive neurons (Shibata \& Blatteis, 1991).

\section{Conclusion}

This case study demonstrated that teething is associated with fever. This case also shows that teething induced fever can cause unnecessary use of anti-malarial drugs and antibiotics. Indiscriminate use of anti-malarial drugs and antibiotics is likely to be practiced among children aging 6-20 months with teething fever. Though not all children are affected by teething induced fever, we appeal for the health care workers to consider teething as one of cause of fever among children at this age group.

\section{Acknowledgements}

We acknowledge the mother of the study patient for the cooperation in giving history of this case study.

\section{Declaration of interest}

There is no conflict of interest that could be perceived as prejudicing the impartiality of the case reported.

\section{References}

Coreil, J., Price, L. \& Barkey, N. (1995) Recognition and management of teething diarrhea among Florida pediatricians. Clinical Pediatrics 34: 591-596.

Cunha, R.F., Garcia, L.D., Carvalho Pugliesi, D.M. \& Murata, S.S. (2004) Systemic and local teething disturbances: prevalence in a clinic for infants. Journal of Dentistry for Children 71: 24-26.

Elmquist, J.K., Breder, C.D., Sherin, J.E., Scammell, T.E., Hickey, W.F., Dewitt, D. \& Saper, C.B. (1997) Intravenous lipopolysaccharide induces cyclooxygenase 2 -like immunoreactivity in rat brain perivascular microglia and meningeal macrophages. Journal of Comparative Neurology 381: 119-129.

Jaber, L., Cohen, I. \& Mor, A. (1992) Fever associated with teething. Archives of Disease in Childhood 67: 233-234.

Kiran, K., Swati, T., Kamala, B. \& Jaiswal, D. (2011) Prevalence of systemic and local disturbances in infants during primary teeth eruption: a clinical study. European Journal of Paediatric Dentistry 12: 249-252.

Kliegman, R.M., Behrman, R.E., Jenson, H.B. \& Stanton, B.M.(2007) Nelson textbook of pediatrics, Elsevier Health Sciences.

Krause, A., Hohberg, B., Heine, F., John, M., Burmester, G. R. \& Witt, C. (1997) Cytokines derived from alveolar macrophages induce fever after bronchoscopy and bronchoalveolar lavage. American journal of Respiratory and Critical Care Medicine 155: 1793-1797.

Leung, A. (1989) Teething. American Family Physician 39: 131-134.

Oziegbe, E., Folayan, M., Adekoya-Sofowora, C., Esan, T. \& Owotade, F. (2009) Teething problems and parental beliefs in Nigeria. The Journal of Contemporary Dental Practice 10:75-82.

Shapira, J., Berenstein-Ajzman, G., Engelhard, D., Cahan, S., Kalickman, I. \& Barak, V. (2003) Cytokine levels in gingival crevicular fluid of erupting primary teeth correlated with systemic disturbances accompanying teething. Pediatric Dentistry 25: 441-448. 
Shibata, M. \& Blatteis, C. M. (1991) Differential effects of cytokines on thermosensitive neurons in guinea pig preoptic area slices. American Journal of Physiology-Regulatory, Integrative and Comparative Physiology 261: R1096-R1103.

Silveira, R. \& Procianoy, R. (1998) Plasmatic levels of interleukin-1beta and interleukin-6 in newborn infants with fever. Jornal de Pediatria 75: 29-33.

Wake, M. \& Hesketh, K. (2002) Teething symptoms: cross sectional survey of five groups of child health professionals. British Medical Journal 325, 814.

Wake, M., Hesketh, K. \& Allen, M. (1999) Parent beliefs about infant teething: a survey of Australian parents. Journal of Paediatrics and Child Health 35: 446-449.

Wake, M., Hesketh, K. \& Lucas, J. (2000) Teething and tooth eruption in infants: a cohort study. Pediatrics 106: 1374-1379.

Yoo, H., Kang, J., Yang, S., Yong, J., Moon, J., Kim, M., Jung, J., Koh, J., Kim, W. \& Oh, W. (2011) Differential expression of cxcl-14 during eruptive movement of rat molar germs. Journal of Experimental Zoology Part B: Molecular and Developmental Evolution 316: 418-426. 